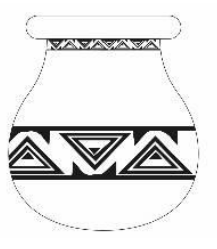

\title{
CLARICE COMO UMA EXPERIÊNCIA FILOSÓFICA
}

\author{
Maria dos Remédios de Brito ${ }^{1}$
}

Dhemersson Warly Santos Costa ${ }^{2}$

\begin{abstract}
Resumo: Literatura e filosofia, filosofia e literatura, há tensionamentos e algumas vezes ressonâncias, outras vezes um movimento de completa crítica e tentativas de separação radical. Pensa-se nos possíveis toques desses saberes e como os mesmos podem se enriquecer com seus limites. As perguntas que movem esse ensaio são: A filosofia passa pela obra de Clarice Lispector? De que forma Clarice promove uma experiência filosófica? Os argumentos são tangenciados pela filosofia francesa de Gilles Deleuze. Clarice Lispector, escritora, contudo, configura em sua obra fabulatória um laboratório imaginativo para o pensamento, e se não pensa pelo conceito, faz filosofia por sua atitude, por expressar, pela literatura, a pergunta filosófica.
\end{abstract}

Palavras-chave: Filosofia; Literatura; Clarice Lispector.

\section{CLARICE AS A PHILOSOFHICAL EXPERIENCE}

\begin{abstract}
Literature and philosophy, philosophy and literature, there are tensions and sometimes resonances, other times a movement of complete criticism and attempts at radical separation. One thinks about the possible touches of this knowledge and how they can enrich themselves with their limits. The questions that move this essay are: Does philosophy pass through the work of Clarice Lispector? How does Clarice promote a philosophical experience? The arguments are tangent to the French philosophy of Gilles Deleuze. Clarice Lispector, writer, however, configures in her fabulous work an imaginative laboratory for thought and if she does not think for the concept, she does philosophy for her attitude, for expressing, through literature, the philosophical question.
\end{abstract}

Keywords: Philosophy; Literature; Clarice Lispector.

\footnotetext{
${ }^{1}$ Professora da Universidade Federal do Pará.

${ }^{2}$ Doutorando em Educação em Ciências (IEMCI/UFPA).
} 
Mas o instante já é um pirilampo que acende e apaga, acende e apaga...

(Clarice Lispector, 1998a, p. 20)

Filosofia e Literatura aparecem com seus tensionamentos e quem sabe ressonâncias ${ }^{3}$. Há, também, movimentos contrários de distanciá-las, enquadrando-as dentro de muros disciplinares, onde cada uma, ao seu modo, agencia um estilo de criação, um modo de movimentar o pensamento. E se há na literatura um tipo de pensamento que não seria possível ser encontrado na filosofia, daí não se tornar apreciado na "cidade filosófica", foi nos departamentos de literatura que a filosofia sempre fora acolhida.

Não se quer entrar no que seria a natureza da literatura para se dizer como tal, pois se parte da ideia de que um texto dito literário pode não pertencer apenas a um gênero, acompanhando o próprio desenho das obras de Clarice Lispector que se recusa a se definir ou a se enquadrar ${ }^{4}$. Provavelmente a escritora entendia que tais criações não estavam nas árvores como frutos, mas ligadas a certas convenções que vão se transformando ao longo dos tempos. As poéticas e estéticas são históricas e acompanham os movimentos culturais com seus tipos de racionalidades, portanto, a literatura não tem uma essência e uma naturalização, Derrida nos dá essa informação em seu texto La loi du genre (1991).

A literatura de Clarice Lispector se desfaz das identidades e às vezes parece rodopiar em outros discursos que ressoam na filosofia, na política, na sociologia, é que por razões internas ao texto e aos interesses da escritora a sua literatura abre-se a outros mundos, dialogando com diferentes saberes e com outras questões artísticas, como se Clarice colocasse para o seu leitor que a literatura compõe uma impossibilidade de autoidentificação. Sua inscrição possível seria abrir o mundo, ampliar a vida, promover novas relações com a existência, dar distintas formas para o pensamento. Com isso, esse tipo de compreensão ressoa na filosofia de modo estranho, pois mostra o deslocamento, por exemplo, da pergunta

\footnotetext{
${ }^{3}$ Interessante pontuar, à guisa de exemplo, as contribuições de Benedito Nunes. Literatura e Filosofia são perspectivas centrais em sua obra, tecendo diálogos atravessados pela transversalidade e convergência com que enfoca Literatura e Filosofia.

${ }^{4}$ É vital que se tenha em mente que o esforço deste ensaio não é para enquadrar Clarice Lispector dentro do ofício de filósofo. Essa autora recusava, inclusive, a ideia de escritor como ofício. Em entrevistas, e até mesmo em fragmentos de seus textos, Clarice explica que a escrita é uma necessidade do seu corpo, que não escreve para contemplar os anseios do mercado, não faz da escrita uma profissão, pois estes movimentos inibem seu processo criador. Clarice prefere se afastar das classificações, das categorias, prefere fazer seus passeios livres pela literatura, pela pintura e, em nossa interpretação, pela filosofia, sem a preocupação com a obediência "aos modos de fazer" instituídos, isto é, seguir os preceitos que instauram um certo gênero ou uma certa técnica.
} 
metafísica $o$ que é? E se a literatura leva essa indagação para o seu fazer, jamais suas respostas oferecem garantias.

Este ensaio não tem como preocupação promover qualquer tipo de esgotamento desse problema, antes, uma provocação, muito mais do que respostas. O fio que traça essa escrita traz essa abertura a partir da sua questão: a filosofia passa pela obra de Clarice Lispector? De que forma Clarice promove uma experiência filosófica? Os argumentos são tangenciados pela filosofia francesa de Gilles Deleuze, este que fez de sua filosofia um trabalho de rigor primordial com o não filosófico, deixando a filosofia ser arrastada pelo estrangeiro, para ali brotar conceitos. Não há preocupação em fazer aproximações de Deleuze e Clarice, e nem de Clarice e Deleuze, mas demarcar a atitude da escrita e da posição, o ar que emana dessas linhas.

\section{II}

A coisa tem um instante em que ela é. Quero apossar-me do é da coisa (Clarice Lispector, 1998a, p.13)

Gilles Deleuze, um filósofo por excelência, escreveu com grandes pensadores da história da filosofia - Nietzsche, Espinosa, Hume, Foucault, Bergson - mas também escreveu através de pintores, músicos, poetas, cineastas e escritores literários, mobilizando, efetivamente, questões filosóficas.

Em O que é a filosofia?, Deleuze e Guattari $(2010,1991)$ ponderam que há uma diferenciação entre três campos dos saberes: a arte, a ciência e a filosofia. Enquanto a arte trabalha com a criação de afectos e perceptos, a ciência opera com funções e a filosofia no trabalho conceitual. Entre eles não há hierarquia, nem sobreposição, mas intercruzamentos, conexões na medida em que os três são criadores. Quando Deleuze convoca a literatura em suas obras, não é para tecer uma reflexão sobre a teoria literária, também não é uma mera exemplificação de conceitos ou legitimação, mas para se contagiar com o que há de mais potente na literatura para fazer pensar (DELEUZE; PARNET, 1998). Pouco interessa o aspecto léxico da obra ou a interpretação literária, importa o ritmo linguístico, o revolucionário, a gagueira que ela produz na língua, os problemas que a literatura é capaz de provocar (BRITO, 2015). A literatura, com seus blocos de afectos e perceptos (DELEUZE; GUATTARI, 2010), é uma travessia que leva o pensamento a pensar, uma experiência que 
instiga o impensável no pensamento, o indizível da palavra, o inaudível dos sons (DELEUZE, 2011).

Nesse cenário, o que interessa é o estilo mobilizado por esse pensador que, mesmo preocupado com questões filosóficas, faz suas travessias pela arte (literária) como um filósofo viajante, catador de histórias, de experiências e de modos de vida errantes, o que não fez dele, essencialmente, um crítico literário. Com isso, questiona-se, então, se é possível inversamente pensar no escritor literário como aquele que também pode fazer travessias pela filosofia, pensa-se que sim, parece possível um devir ${ }^{5}$-filosofia em Clarice Lispector.

\section{III}

A invenção do hoje é o meu único meio de instaurar o futuro (Clarice Lispector, 1998a, p.13)

A obra literária de Clarice Lispector vem sendo constantemente mobilizada em pesquisas acadêmicas, não apenas no campo da Literatura, mas também da Psicanálise, da Educação e da Filosofia, por exemplo. Na Filosofia, em especial, alguns estudiosos buscam inspiração nos escritos de Lispector para mobilizar suas próprias questões filosóficas. À guisa de exemplo, Benedito Nunes (2009), um dos principais comentadores da autora no Brasil, opera algumas digressões sobre a experiência da náusea que aproxima Clarice e Sartre, bem como a perspectiva existencialista nos textos clariceanos, endossados por uma analítica filosófica de Heidegger e Kierkegaard.

Na obra Perto do Coração Selvagem, primeiro romance publicado por Clarice, é constantemente investigada a presença do pensamento de Espinosa, o qual aparece, explicitamente, nas falas de Otávio e, principalmente, nas inquietações de Joana (GAZZINELLI, 2015). São múltiplas as entradas filosóficas escavadas nas obras de Clarice, pois sua escrita abre passagem a personagens (mulheres) inquietas com a sua existência,

\footnotetext{
${ }^{5} \mathrm{O}$ devir, aqui, é um conceito emprestado da Filosofia da Diferença de Gilles Deleuze que retoma a ideia de "tornar-se". Nada tem de metafórico, não se trata de atingir uma forma, não se trata de imitar, mas de escapar de uma forma dominante, fissurar os códigos disciplinadores, criar para si linhas de fugas inventivas. Devir é um exercício de resistência, de buscar nos modos de vida marginais, errantes, minoritários, sua potência inventiva. Por essas linhas, devir é entrar em zonas de vizinhança com essas forças dissonantes, deixar-se contagiar por elas. Com isso pensar em devir-filósofo nada tem de metafórico, não se deseja torna-se filósofo, mas entrar em zonas de vizinhança, contaminar-se com aquilo que há de mais potente na filosofia para fazer do pensamento uma experiência singular, fazendo-a proliferar em multiplicidade.
} 
personagens que carregam um certo desassossego, colocam em perspectiva a própria ideia de humano (CURI, 2001).

Clarice escreve por meio de mulheres: Joana (1990), Lucrécia Neves (1998), Lori (1998c), Macabéa (1998d). Estas carregam em seus corpos o sintoma do perecível humano, a angústia de existir, o desafio que é ser mulher em um mundo que define e aprisiona em normas de condutas. Essas são apenas algumas das questões existenciais lançadas por Lispector. Em seus textos, temas como a solidão, o inumano, a culpa, a sexualidade, a moralidade, o silêncio, o corpo, Deus, a consciência, o desejo, o tempo, a morte... são mobilizados como uma espécie de mapa, nele brotam possibilidades de resistência, de criação de mundos possíveis. Por essas veredas, Clarice coloca em perspectiva os problemas deste mundo, sua literatura se espalha sobre um plano de composição, o que remete até mesmo a uma questão ética: pensar este mundo, os problemas desta Terra, como fazer a vida proliferar em meio à barbárie, à disciplina, à toda uma moralidade que contaminou o ser vivente, tornando-o escravo de si e do outro. Com isso, Clarice Lispector faz no ato de escrita literária suas travessias pela filosofia na medida em que suas personagens mobilizam o pensamento. Por essas linhas, perspectivam-se estilhaços de filosofia, ou uma espécie de “emoção' filosófica, o sentimento de existência como excesso, o 'ser-em-demasia'”, no dizer de Derrida (2014, p. 50), tudo isso atravessa sua obra.

IV

A causa é a matéria do passado (Clarice Lispector, 1998, p. 16).

Clarice como uma experiência filosófica. Eis o argumento que anima esta digressão, o que demanda, de antemão, ponderar o que se entende por filosofia. Para isso, recorre-se a Deleuze e Guattari. Em $O$ que é a filosofia?, eles sustentam que a filosofia é a criação de conceitos, "a filosofia é a arte de formar, de inventar, de fabricar conceitos" (2010, p. 10). O filósofo é o artesão, aquele a quem compete o ato criador. O filósofo manuseia os conceitos, operando deslocamentos e movimentações. O conceito, por sua vez, é um emaranhado de complexas relações, uma multiplicidade, não se trata de representar uma imagem, antes é uma paisagem que remete a um problema, e é em função do problema que o conceito é lapidado, como lembram Deleuze e Guattari, "todo conceito remete a um problema, a problemas sem os quais não teria sentido, e que só podem ser isolados ou compreendidos na medida de sua 
solução" (2010, p. 25). Os conceitos não estão para serem decalcados, eles participam dessa vida, são os problemas que instigam a criação dos conceitos. Por isso, só se cria conceitos sobre um plano de imanência (BRITO, 2017). O filósofo é como um médico para o mundo, ele mergulha no caos, percebe o mundo que o atravessa, suas entranhas. O filósofo é aquele que viu e ouviu uma força estranhamente sagrada, seu corpo, médico, filósofo, procura diagnosticar a doença do mundo, os poderes tristes, os sintomas que adoecem os corpos e limitam as potências criativas do vivente humano. O filósofo mobiliza um trabalho ético: libertar o pensamento, torná-lo crítico, torná-lo capaz de fazer a vida ser vista em toda sua complexidade.

O trabalho do filósofo é, efetivamente, com os problemas do mundo, com o que aprisiona a vida, o corpo, impedindo-o de criar. Em Diferença e Repetição, Deleuze (2006) pontua que, na história da filosofia, há uma imagem do pensamento que tomou conta da sociedade: o pensamento da representação. A vida é representada pelo senso comum, pelos saberes instituídos como verdade. Faze-se da nossa existência um ato representacional. Reproduz-se uma série de códigos sociais e, com isso, perde-se a potência criadora. Deixamos escapar a possibilidade de criar modos existenciais que destoam do semelhante, do igual, da linguagem instituída. O pensamento parece fixado, paralisado em normas, em condutas, em modos de ser.

Romper com essa imagem dogmática do pensamento não é uma tarefa fácil, é um combate diário com o monstro que habita os indivíduos, uma luta contra a vergonha de ser "o que se é”. Uma batalha que só é possível pela experiência com o fora, com aquilo que tira do lugar, uma força estranha que violenta o pensamento, um choque com os signos, com os problemas que mobilizam aprendizados. O "problema", na perspectiva da diferença, parece ser muito mais interessante do que as respostas.

Pensar, por essas linhas, não é um ato natural, não se pensa sozinho (SCHOPKE, 2012). É preciso uma força estranha, um encontro afetivo que atravesse o corpo, arrastando-o para outros mundos, para o deserto ou, ainda, para o jardim botânico. Pensar é uma violência que se dá a partir dos encontros com os signos. As imagens, os sons, os filmes, a pintura, os encontros, a chuva que cai, o cheiro, o sabor, as letras, as palavras, a literatura... Qualquer coisa capaz de afetar o corpo pode ser entendida como um signo "desde que permita a interpretação como uma ação de significar o signo, atribuindo-lhe sentido, isto é, seja capaz de disparar sensações e pensamentos inusitados na natureza em questão" (NEUSCHARANK e OLIVEIRA, 2017, p. 585). 
Os signos são forças singulares que afetam todos e os arrastam para os outros territórios, abalando nossas certezas (DELEUZE, 2003). É um aprendizado que ativa o corpo singular. Não há como prever a fatalidade de um encontro com os signos, cada corpo se afeta de uma maneira, os corpos produzem algo diferente a cada relação com o signo. Uma palavra, um gesto, uma imagem pode desencadear aprendizados de uma vida. Os signos mobilizam desejos, blocos de sensações que inspiram a criação de outras composições, outras vidas regadas de encontros alegres, onde o corpo, torna-se vetor de experimentações, um corpo aberto aos devires. Ora, em que medida isso faz de Clarice uma experiência filosófica, se antes fora demarcado os limites da arte, da ciência e da filosofia? Clarice cria blocos de sensações, não há dúvida, promove com todo rigor o ato de fabular, porém, tomando por outro ângulo, a escritora, por meio da imaginação, por blocos de perceptos e afetos nos coloca a atitude filosófica, porque, em sua obra, passa uma "emoção filosófica", um certo gosto pelo filosófico, como se tomasse da filosofia as armaduras para pensar a literatura, com isso faz da sua literatura um alinhamento pela filosofia, mesmo que essas linhas possam ser estranhas, pois, Clarice não foi aos filósofos para pensar como eles, mas por entre eles. Clarice que se coloca como uma escritora que se interroga, que levanta questões, que busca colocar na linguagem o componente da dúvida. Nas suas obras literárias não deixa os personagens sem essa agitação no corpo, tal como o filósofo, o criador de problemas. É preciso deixar claro que Clarice Lispector não pensa seus escritos conceitualmente, pois cria arte e não filosofia, nem por isso deixa de produzir um mosaico percorrido pelo pensamento filosófico emissor de signos. O saber filosófico de Clarice não se dá pela via do conceito, se arma pelo intuitivo, pelo imaginativo, como se Clarice fizesse um alerta aos próprios filósofos para não serem tão radicais entre os limites dos saberes. Como amante da filosofia, diz para o amado a sua não completude em si mesma, como quem diz que a filosofia para ser filosofia precisa do não filosófico, assim como a própria literatura para se fazer literatura deve caminhar por outras searas. Por essa leitura também se poderia dizer que Clarice provoca a filosofia na sua própria linguagem, como se pedisse para a mesma libertar certas regras, deslocar perspectivas, desconfiar de certas definições, abrir a linguagem, contudo, isso retomaria as distinções entre uma e outra, o que não é interesse deste ensaio. Insiste-se Clarice como uma experiência filosófica, pois ela mantém uma atitude, uma emoção filosófica em sua literatura, expressando em suas obras a sua visão de mundo, de homem, de vida, de liberdade, de trágico. Há toda uma perspectiva trágica na obra literária de Clarice que valeria ser investigada. 
Em Clarice Lispector, os encontros das suas personagens com os signos figuram como um traço marcante no estilo da autora (CURI, 2001). Em muitos dos seus romances, a trama se desenrola a partir de um encontro intensivo que arrasta as personagens para longe das zonas de conforto, levando-as a questionar sua própria existência: “Quem sou eu? ”; "O que é ser mulher? ", “O que é ser feliz?”, “o que é a morte?”, “ O que é viver”? Se tais indagações não têm respostas pelo argumento filosófico, não deixa de ser uma questão filosófica, essa atitude, essa emoção se arrasta na obra de Clarice.

No conto Amor (1982), Clarice Lispector apresenta a história de Ana. Mulher, mãe de família e dona de casa. Ana é uma mãe comprometida com a educação dos seus filhos e o cuidado do marido. Seus dias são preenchidos com tarefas domésticas. Entre uma tarefa e outra, Ana vai à feira, ao supermercado, à farmácia. Cumpre fielmente com o destino de sua existência. Certa vez, voltando da feira, Ana avista, da janela do bonde, um homem cego, mascando chicletes e olhando em direção ao horizonte "sem sofrimento, com os olhos abertos" (LISPECTOR, 1982, p. 24). Os olhos de Ana estão fixados nessa imagem, paralisados em uma espécie de transe, a qual só é rompida com a "arrancada súbita" do bonde. A sacola de compras, depositada em seu colo, cai no chão. As frutas se espalham. Os ovos quebram, revelando toda sua viscosidade ao mundo. Ana também é "quebrada". Esse acontecimento, demasiadamente banal, desperta um monstro interior que habita o corpo de Ana, um animal feroz até então adormecido. O caos se instaura em seu corpo. Enfurecida, Ana abandona suas compras, passa a perambular, sem destino certo, pelo mundo. Em certa medida, Ana chega ao jardim botânico, algo chama sua atenção:

Inquieta, olhou em torno. Os ramos se balançavam, as sombras vacilavam no chão. Um pardal ciscava na terra. E de repente, com mal-estar, pareceu-lhe ter caído numa emboscada. Fazia-se no Jardim um trabalho secreto do qual ela começava a se aperceber. Nas árvores as frutas eram pretas, doces como mel. Havia no chão caroços secos cheios de circunvoluções, como pequenos cérebros apodrecidos. $\mathrm{O}$ banco estava manchado de sucos roxos. Com suavidade intensa rumorejavam as águas. No tronco da árvore pregavam-se as luxuosas patas de uma aranha. A crueza do mundo era tranquila. $\mathrm{O}$ assassinato era profundo. E a morte não era o que pensávamos. (LISPECTOR, 1982, p. 24).

No jardim, Ana é novamente imobilizada. A mulher se vê diante da "crueldade do mundo", da morte do vivente habituado a viver. O encontro de Ana com o cego, com a crueza 
da vida no jardim botânico, instaura no seu corpo um abalo nas certezas, nas verdades universais que conduziam a sua existência. Um encontro que remete a um trabalho ético de Ana consigo mesma, voltar suas questões, seus problemas, para si mesma. Ana olha para si, não por um narcisismo latente, mas porque é sobre seu corpo-mulher que os poderes tristes atuam, impedindo-a de criar outros modos de existência, de fazer do pensamento uma aventura, uma abertura para outras estéticas da existência.

Em Água Viva (1998a), na forma fragmentária, a questão que se coloca é o instante, o desejo de captar a quarta dimensão do instante, do agora, do presente que passa...O tempo, visto de forma fugidia, em fluxo, pois cada agora já foi, assim como cada coisa goza do seu agora, o que se diz não é, deseja o é da coisa, mas sabe que o é não se pode atingir. Também toma a vida, a liberdade, a solidão, a morte, o silêncio. Os temas vão aparecendo e ao mesmo tempo escapando. Retoma a problemática do eu e se interroga sobre o que seria "eu".

Ora, alguns passeios foram feitos em suas obras, não foi para provar que Clarice é filósofa, mas para dizer, acima de tudo, sobre a fascinante singularidade dessa escritora em elaborar questões filosóficas, que são pertinentes à filosofia, dando ao leitor um gesto de amor pelo pensamento, ao mesmo tempo ensinando um certo funcionamento de criar problemas, trazendo uma força filosófica na experiência de pensar com a literatura, força provocativa para olhar o mundo. Sim, pois antes do conteúdo filosófico, ler Clarice é também entrar em uma experiência filosófica. Contudo, isso não é uma verdade, mas apenas uma interpretação, que se siga nessas aberturas, já que há muitas formas de ver o mundo.

\section{REFERÊNCIAS BIBLIOGRÁFICAS}

BRITO, M. R. Entre as linhas da educação e da diferença. São Paulo: Editora Livraria da Física, 2015.

BRITO, M. R. A Filosofia como criadora de conceitos. In: Maria dos Remédios de Brito; Helane Súzia Silva dos Santos. (Org.). Variações Deleuzianas: Educação, ciência, arte e.... 1ed.São Paulo: LF, 2017, v. 1, p. 15-28.

CURI, S. A escritura nômade em Clarice Lispector. Chapecó: Argos, 2001.

DELEUZE, G.; GUATTARI, F. O que é a filosofia. São Paulo: Ed. 34, 2010.

DELEUZE, G.; GUATTARI, F. Qu'est-ce que la philosophie? Paris: Minuit, 1991.

DELEUZE, G.; PARNET, C. Diálogos. São Paulo: Escuta, 1998. 
DELEUZE, G. Diferença e repetição. Rio de Janeiro: Graal, 2006.

DELEUZE, G. Crítica e clínica. São Paulo: Ed. 34, 2011.

DELEUZE, Gilles. Proust e os signos. Rio de Janeiro: Forense Universitária, 2003.

DERRIDA, J. La loi du genre. Paris. Seuil, 1991.

DERRIDA, J. Essa estranha instituição chamada Literatura. Belo Horizonte: Editora UFMG, 2014.

GAZZINELLI, G. G. Uma leitura espinozista de Perto do coração selvagem. Artefilosofia, n. 19, p. 32-45, 2015.

LISPECTOR, C. Laços de Família. Rio de Janeiro: José Olympio Editora: 1982.

LISPECTOR, C. Perto do coração selvagem. Rio de Janeiro: Francisco Alves, 1990.

LISPECTOR, C. Água viva. Rio de Janeiro: Rocco, 1998a.

LISPECTOR, C. A cidade sitiada. Rio de Janeiro: Rocco, $1998 \mathrm{~b}$.

LISPECTOR, C. Uma aprendizagem ou O livro dos prazeres. Rio de Janeiro: Rocco, 1998c.

LISPECTOR, C. A hora da estrela. Rio de Janeiro: Rocco, 1998d.

NEUSCHARANK, A; OLIVEIRA, M. O. Encontros com signos: possibilidades para pensar a aprendizagem no contexto da educação. Revista Educação, v. 42 n.3, p.585-596, 2017.

NUNES, B. O mundo de Clarice Lispector. Manaus: Edições Governo do Estado do Amazonas, 2009.

SCHÖPKE, R. Por uma filosofia da diferença: Gilles Deleuze, o pensador nômade. Rio de Janeiro: Contraponto, 2012. 